\title{
Influence of annealing temperature on the structural and optical properties of $\mathrm{As}_{30} \mathrm{Te}_{70}$ thin films
}

\author{
A.M. Abd-Elnaiem ${ }^{1, *}$, M. Mohamed ${ }^{1}$, R.M. Hassan $^{1,2}$, A.A. Abu-Sehly ${ }^{1}$, \\ M.A. ABDEL-RAHIM ${ }^{1}$, M.M. HAFIZ ${ }^{1}$ \\ ${ }^{1}$ Physics Department, Faculty of Science, Assiut University, 71516 Assiut, Egypt \\ ${ }^{2}$ Physics Department, Faculty of Education, Zingiber, Aden University, Yemen
}

\begin{abstract}
Chalcogenide glasses have attracted much attention largely due to their interesting physical and chemical properties. Though few published articles exist on the As-Te system, little is known about the optical properties of eutectic or near eutectic composition of As-Te system upon heat treatment. Therefore, this paper reports the effects of annealing temperature on the structural and optical parameters of $\mathrm{As}_{30} \mathrm{Te}_{70}$ thin films. The bulk and thin films of $150 \mathrm{~nm}$ thick $\mathrm{As}_{30} \mathrm{Te}_{70}$ chalcogenide glasses were prepared by melt-quenching and thermal evaporation techniques, respectively. The glass transition and crystallization reactions of the bulk samples were investigated using differential scanning calorimetry (DSC). The influence of annealing temperature on the transformation of the crystal structure was studied by X-ray diffraction (XRD), while the surface morphology of the annealed samples was examined using scanning electron microscope (SEM). The optical band gap, refractive index and extinction coefficient were also calculated. The DSC scans showed that the melting temperature remains constant at $636.56 \mathrm{~K}$. In addition, other characteristic temperatures such as the glass transition temperature, the onset crystallization temperature, and the crystallization peak temperature increase with increasing the heating rate. The crystalline phases for the as-prepared and annealed films consist of orthorhombic As, hexagonal Te, and monoclinic $\mathrm{As}_{2} \mathrm{Te}_{3}$ phases. Furthermore, the average crystallite size, strain, and dislocation density depend on the annealing temperature. The optical absorption results revealed that the investigated films have a direct transition, and their optical energy gap decreases from $1.82 \mathrm{eV}$ to $1.49 \mathrm{eV}$ as the annealing temperature increases up to $433 \mathrm{~K}$. However, the refractive index, extinction coefficient, dielectric constant and the ratio of free carrier concentration to its effective mass, increase with increasing the annealing temperature.
\end{abstract}

Keywords: chalcogenide glasses; As-Te system; thin films; structural, optical parameters; thermal evaporation

\section{Introduction}

Chalcogenide glasses have attracted much interest in both fundamental research and technological applications. Their interesting physical and chemical properties have been explored for numerous applications such as switching elements, infrared optical elements, optical fibers, optical transmission media, phase-change optical disks as well as in the fields of xerography and novel memory devices $[1,2]$. Similar to most thin films, the properties and subsequent applications of these glasses depend largely on the preparation history and heat treatment. For example, the memory-type and threshold-type switching are obtained on the basis of different rates of crystallization.

*E-mail: alaa.abd-elnaiem@ science.au.edu.eg
Among V-VI glasses is the As-Te system, which exhibits a continuous transformation from a semiconductor to a metallic state when heated [3, 4]. This eutectic binary system belongs to the archetypical chalcogenide glass-forming system which is characterized by high crystallization ability. In addition, its semicoductor-metal transition occurs at a relatively low temperature just above the melting point [4]. The bulk As-Te chalcogenide glass exhibits a random covalent network without any preferred bonding. It can be obtained by melt-quench technique over a wide range of compositions (20 at.\% to 60 at.\% of As) [5]. On the other hand, As-Te thin films can be prepared by different methods such as sputtering, thermal evaporation, wet chemistry techniques [6]. Of these methods, thermal evaporation is commonly used due to its simplicity, low cost, reproducibility, and 
scalability. Moreover, such films are highly uniform and adhere strongly to the substrates.

The As-Te glasses have been studied for various applications based on their promising properties [1-6]. The effect of thermal annealing on the optical properties of chalcogenide glasses has been studied and interpreted according to the density of states model in amorphous materials proposed by Mott et al. [7]. In addition to the structural and thermal studies [8-16], Cornet et al. [15, 16] explored also the effect of structure and glass-forming ability of As-Te on its physical properties. They found that As-rich glasses have stronger covalent bonds while Te-rich glass shows the presence of threefold coordinated Te sites which enhances its metallic character and weakens the difference between crystalline and glass states. Recently, different studies on the binary As-Te glasses as well as As-Te incorporated with other elements have been reported [17-22].

Although few articles have been published on As-Te system [1-22], little is known about the optical properties of eutectic composition (73 at.\% of $\mathrm{Te}$ ) or near eutectic of As-Te film upon heat treatment. Therefore, this paper reports the effects of annealing temperature on the structural and optical parameters of $\mathrm{As}_{30} \mathrm{Te}_{70}$ thin films. The structure and phase changes have been correlated with the optical properties such as dispersion and optical constants.

\section{Materials and methods}

$\mathrm{As}_{30} \mathrm{Te}_{70}$ chalcogenide glasses were prepared by melt-quench technique. As and Te, of $99.99 \%$ purity were purchased from Aldrich Chem., Co. (USA), and weighted according to their atomic percentage. They were then placed in silicaglass ampoules and sealed under a vacuum of $1.33 \times 10^{-3} \mathrm{~Pa}$. The sealed ampoules were heated gradually in a furnace to $1100 \mathrm{~K}$ and then held at that temperature for $24 \mathrm{~h}$. The melt was continuously stirred to ensure the two elements mixed homogeneously. Thereafter, the ampoules were quenched in ice-cold water. The thermal behavior of the as-prepared powdered $\mathrm{As}_{30} \mathrm{Te}_{70}$ sample was investigated using a Differential
Scanning Calorimeter (TA-Q20) under a nitrogen atmosphere at different heating rates (from $5 \mathrm{~K} / \mathrm{min}$ to $25 \mathrm{~K} / \mathrm{min}$ ). The errors of the determined characteristic temperatures were about $\pm 1 \mathrm{~K}$.

$\mathrm{As}_{30} \mathrm{Te}_{70}$ thin films were deposited by thermal evaporation under a vacuum of $1.33 \times 10^{-3} \mathrm{~Pa}$ using E-306 coating system on ultrasonically cleaned glass substrates. The thicknesses of the as-deposited films were adjusted to be almost the same $(150 \mathrm{~nm} \pm 2 \%)$. The thin films were annealed for $1 \mathrm{~h}$ under a constant flow rate of nitrogen gas at various temperatures $(373 \mathrm{~K}, 393 \mathrm{~K}$, $433 \mathrm{~K}, 473 \mathrm{~K}$ and $513 \mathrm{~K}$ ). The crystalline phases of the as-deposited and annealed films were examined using X-ray diffractometer (Philips PW 1710) with $\mathrm{CuK} \alpha$ radiation of $1.5418 \AA$ A wavelength. The microstructure of the annealed samples was observed with JOEL-JSM-5400LV scanning electron microscope (SEM). The optical transmittance (T) and reflectance $(\mathrm{R})$ of both as-deposited and annealed films were measured at room temperature (RT) using a double-beam computer-controlled spectrophotometer (SHIMADZU UV-2101) in the wavelength range of $200 \mathrm{~nm}$ to $2500 \mathrm{~nm}$.

\section{Results and discussion}

\subsection{Structural analysis of the thin films}

The differential scanning calorimetric (DSC) curves (Fig. 1) indicate that $\mathrm{As}_{30} \mathrm{Te}_{70}$ bulk exhibits an endothermic glass transition, two distinct exothermic crystallization reactions, and an endothermic melting peak for all the heating rates considered. With increasing the heating rate, the glass transition temperature $\left(\mathrm{T}_{\mathrm{g}}\right)$, the onset crystallization temperatures $\left(\mathrm{T}_{\mathrm{c} 1}\right.$ and $\left.\mathrm{T}_{\mathrm{c} 2}\right)$ and the crystallization peak temperatures $\left(\mathrm{T}_{\mathrm{p} 1}\right.$ and $\left.\mathrm{T}_{\mathrm{p} 2}\right)$ shifted to a higher temperature while the melting temperature reminded independent of the heating rate.

The endothermic peak observed at $620 \mathrm{~K}$ is related to the transformation of the two solid phases $\left(\mathrm{As}_{2} \mathrm{Te}_{3}+\mathrm{Te}\right)$ to a solid and a liquid phase $\left(\mathrm{As}_{2} \mathrm{Te}_{3}+\right.$ liquid) [23]. The values of these temperatures at different heating rates are presented in Table 1. The value of $\mathrm{T}_{\mathrm{g}}$ can also 
Table 1. Glass transition temperature $\left(T_{\mathrm{g}}\right)$, onset crystallization temperatures $\left(\mathrm{T}_{\mathrm{c} 1}\right.$ and $\left.\mathrm{T}_{\mathrm{c} 2}\right)$, crystallization peak temperatures $\left(\mathrm{T}_{\mathrm{p} 1}\right.$ and $\left.\mathrm{T}_{\mathrm{p} 2}\right)$, and melting temperature $\left(\mathrm{T}_{\mathrm{m}}\right)$ for $\mathrm{As}_{30} \mathrm{Te}_{70}$ bulk glass produced at different heating rates.

\begin{tabular}{ccccccc}
\hline Heating rate $[\mathrm{K} / \mathrm{min}]$ & $\mathrm{T}_{\mathrm{g}}[\mathrm{K}]$ & $\mathrm{T}_{\mathrm{c} 1}[\mathrm{~K}]$ & $\mathrm{T}_{\mathrm{p} 1}[\mathrm{~K}]$ & $\mathrm{T}_{\mathrm{c} 2}[\mathrm{~K}]$ & $\mathrm{T}_{\mathrm{p} 2}[\mathrm{~K}]$ & $\mathrm{T}_{\mathrm{m}}[\mathrm{K}]$ \\
\hline \hline 5 & 384.95 & 413.66 & 424.04 & 531.04 & 544.07 & \\
10 & 389.24 & 421.08 & 430.98 & 530.07 & 550.98 & \\
15 & 391.32 & 422.24 & 435.02 & 537.45 & 555.46 & 636.56 \\
20 & 395.41 & 423.12 & 438.25 & 536.43 & 557.89 & \\
25 & 397.16 & 425.45 & 441.41 & 536.27 & 560.79 & \\
\hline
\end{tabular}

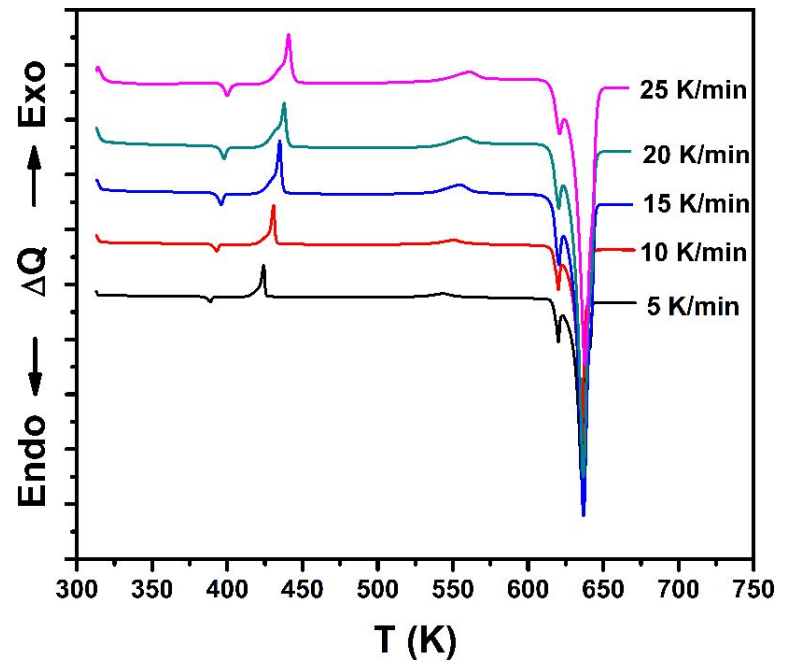

Fig. 1. DSC traces for the $\mathrm{As}_{30} \mathrm{Te}_{70}$ bulk glasses at different heating rates.

be calculated based on coordination number $\langle\mathrm{CN}\rangle$, using the Tanaka formula (equation 1):

$$
T_{g}(K) \approx e^{1.6<C N>+2.3} ; 1 \leqslant<C N>\leqslant 2.7
$$

For $\mathrm{As}_{30} \mathrm{Te}_{70},\langle\mathrm{CN}\rangle=2.3$, the value of $\mathrm{T}_{\mathrm{g}}$ calculated from equation 1 is $395.4 \mathrm{~K}$, which is close to the average value obtained from DSC curves (391.6 K).

From the XRD spectra of the as-prepared films (Fig. 2), the single crystalline peak which is observed at $2 \theta=72.12^{\circ}$ is attributed to the nucleation and crystallization of As phase during the sample preparation. For the annealed samples, however, XRD spectra show that $\mathrm{As}, \mathrm{Te}$, and $\mathrm{As}_{2} \mathrm{Te}_{3}$ phases, having orthorhombic, hexagonal and monoclinic crystal structure, respectively, coexist. The polycrystalline structure of the annealed

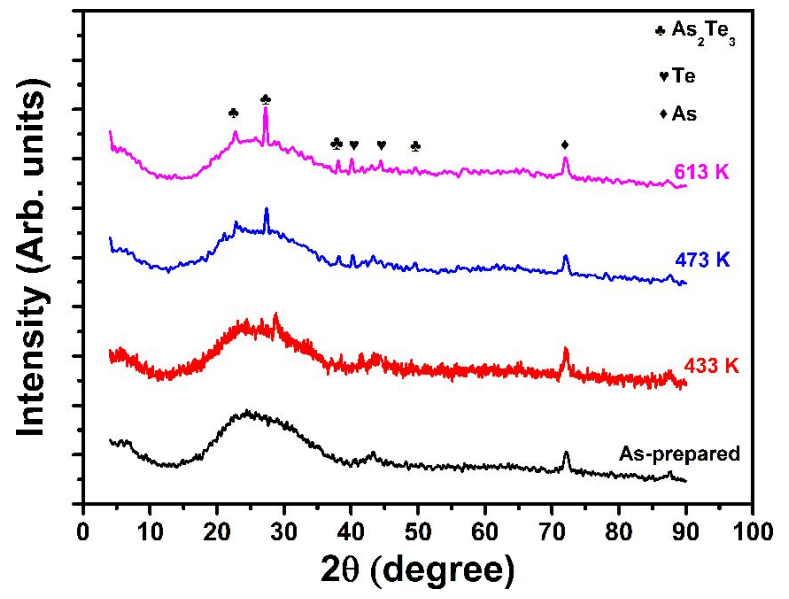

Fig. 2. XRD patterns of the as-prepared and annealed $\mathrm{As}_{30} \mathrm{Te}_{70}$ thin films.

samples is in agreement with the calculated phase diagram of the $\mathrm{As}_{30} \mathrm{Te}_{70}$ system, which largely depends on the annealing temperature.

The average crystallite size $D_{h k l}$ of the formed phases, the dislocation density $\delta$ and the strain $\mu$ of the studied films were calculated according to the following equations [24, 25], respectively:

$$
\begin{gathered}
D_{h k l}=\frac{K \lambda}{\beta_{h k l} \cos (\theta)} \\
\delta=\left(\frac{n_{\delta}}{D_{h k l}}\right) \\
\mu=\left(\frac{\lambda}{D_{\mathrm{hkl}} \cos (\theta)}-\beta_{h k l}\right) \frac{1}{\tan (\theta)}
\end{gathered}
$$

where $\mathrm{K}$ is the Scherrer constant (generally taken as one) which is related to the particle shape, $\theta$ is 
the Bragg angle, $\lambda$ is the wavelength of X-ray, $\beta_{\mathrm{hkl}}$ is the full width at half maximum (FWHM) peak intensity and $\mathrm{n}_{\delta}$ is a factor of unit value at minimum dislocation density.

The errors in the estimated values are less than $3 \%$. It is evident from Table 2 that $D_{\text {hkl }}$ of As, $\mathrm{Te}$ and $\mathrm{As}_{2} \mathrm{Te}_{3}$ phases slightly increased with the annealing temperature, indicating a considerable increase in the volume fraction of the crystalline phases. This confirms that the thermal annealing improves the crystallinity of the investigated thin films. As a single peak is obtained for As phase in both as-prepared and annealed samples, the ratio of the peaks intensity of $\mathrm{As}_{2} \mathrm{Te}_{3}$ and Te phases is about 3:1 which is similar to that obtained from the phase diagram of As-Te system [23]. Conversely, the dislocation density $\delta$ and the strain $\mu$ decreased with the annealing temperature (Table 2). This indicates an inverse relationship between them and the crystallite size.

Based on the SEM images of the samples shown in Fig. 3a, a polycrystalline structure consisting of different phases embedded in an amorphous matrix is observed. The particle size and the fraction of the transformed crystalline phase increased with the annealing temperature (Fig. 3b). On the other hand, very fine rod-like structure homogeneously distributed in the matrix is observed in Fig. 3c. The appearance of such fine rod-like structure could be attributed to the Te-rich eutectic phase. Some of these crystallized particles are interconnected, while few others are isolated.

\subsection{Optical analysis}

\subsubsection{Absorption coefficient}

The spectral distribution of transmittance $T(\lambda)$ and reflectance $R(\lambda)$ of the as-prepared and annealed films of $\mathrm{As}_{30} \mathrm{Te}_{70}$ are shown in Fig. 4. One can observe that the optical transmittance decreases as the annealing temperature increases. This may be due to to the structural transformation of the films during annealing [26, 27]. It can also be seen that the fundamental absorption edge shifts to higher wavelength with increasing the annealing temperature. On the other hand, the reflectance increases with increasing the temperature of thermal annealing. The changes in the transmittance or the reflectance with annealing temperature may be explained using the proportional relationship between free carrier absorption in solids and the number of carriers (and carrier mobility). Since the number of carriers increases during annealing, their absorption in the infrared region increases subsequently.

The absorption coefficient $(\alpha)$ was estimated from the experimental values of $T(\lambda), R(\lambda)$ and the film thickness $d$ using the following relation [28, 29]:

$$
\alpha=\frac{1}{d} \ln \left[\frac{(1-R)^{2}}{T}\right]
$$

As shown in Fig. 5, $\alpha$ increases with increasing both the photon energy and annealing temperature. This behavior could be due to the size effect [27]. Depending on the value of $\alpha$, its spectral distribution can be categorized as high absorption or exponential edge region.

In the high absorption region, $\alpha \geqslant 10^{4} \mathrm{~cm}^{-1}$, the Tauc relation can be applied [7, 30]:

$$
\alpha h v=B\left(h v-E_{g}\right)^{r}
$$

where $\mathrm{h} v$ is the photon energy, B is a constant (which depends on the transition probability), $E_{g}$ is the optical energy gap of the material, and $r$ is $1 / 2$ for direct allowed transition and 2 for indirect allowed transition. For the films under investigation, the best fit for the dependence of $(\alpha h v)^{1 / \mathrm{r}}$ versus $h v$ was obtained when $r=1 / 2$. Thus, the allowed direct transition process is involved for the as-prepared and annealed $\mathrm{As}_{30} \mathrm{Te}_{70}$ thin film which is in an agreement with the results reported in previous studies [31, 32].

The variation of $(\alpha \mathrm{h} v)^{2}$ versus $\mathrm{h} v$ for the asprepared and annealed films is linear at the absorption edge as shown in Fig. 6. The direct band gap can be obtained by extrapolating the linear portion of the curves to zero absorption, and the error of the determined $\mathrm{E}_{\mathrm{g}}$ was about $\pm 0.01 \mathrm{eV}$. Following this approach, the values of the band gap were calculated, and found to decrease from $1.82 \mathrm{eV}$ to $1.48 \mathrm{eV}$ with increasing the annealing temperature up to $433 \mathrm{~K}$. Then, with further increase in 
Table 2. The observed and standard ASTM values of interplanar distances (d), calculated average crystallite size $(D)$, strain $(\mu)$, and dislocation density $(\delta)$ for as-prepared and annealed $\mathrm{As}_{30} \mathrm{Te}_{70}$ thin films.

\begin{tabular}{|c|c|c|c|c|c|c|c|c|c|}
\hline Sample & Phase & h k 1 & $\begin{array}{c}\mathrm{d}[\AA] \\
\text { observed }\end{array}$ & $\begin{array}{c}\mathrm{d}[\AA] \\
\text { ASTM }\end{array}$ & $\begin{array}{c}\text { crystallite size, } \\
\mathrm{D}[\mathrm{nm}]\end{array}$ & $\begin{array}{l}\text { Average crystallite } \\
\text { size, D [nm] }\end{array}$ & $\begin{array}{l}\text { Dislocation density, } \\
\delta, \times 10^{15}\left[\mathrm{~m}^{-2}\right]\end{array}$ & $\begin{array}{c}\text { Strain } \\
{[\mu] \times 10^{-3}}\end{array}$ & $\begin{array}{c}\text { JCDS } \\
\text { Card No. }\end{array}$ \\
\hline As-prepared & As & $\left(\begin{array}{lll}0 & 3 & 4\end{array}\right)$ & 1.312 & 1.310 & 11.99 & 11.99 & 6.96 & 2.83 & $85-1712$ \\
\hline Annealed at $433 \mathrm{~K}$ & As & $\left(\begin{array}{lll}0 & 3 & 4\end{array}\right)$ & 1.312 & 1.310 & 12.82 & 12.82 & 6.08 & 1.89 & $58-1712$ \\
\hline \multirow{6}{*}{ Annealed at $473 \mathrm{~K}$} & As & $\left(\begin{array}{lll}0 & 3 & 4\end{array}\right)$ & 1.312 & 1.310 & 13.69 & 13.69 & 5.34 & 2.65 & $85-1712$ \\
\hline & \multirow{2}{*}{$\mathrm{Te}$} & $\left(\begin{array}{lll}0 & 1 & 1\end{array}\right)$ & 2.241 & 2.2329 & 19.93 & \multirow{2}{*}{20.05} & 2.52 & 1.82 & $85-0556$ \\
\hline & & $\left(\begin{array}{lll}1 & 1 & 1\end{array}\right)$ & 2.039 & 2.0349 & 20.17 & & 2.46 & 1.80 & $79-0736$ \\
\hline & \multirow{3}{*}{$\mathrm{As}_{2} \mathrm{Te}_{3}$} & $\left(\begin{array}{lll}2 & 0 & 2\end{array}\right)$ & 3.894 & 3.8949 & 19.17 & \multirow{3}{*}{20.4} & 2.72 & 1.29 & $72-1685$ \\
\hline & & 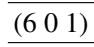 & 2.356 & 3.3614 & 23.78 & & 1.77 & 1.52 & $72-1685$ \\
\hline & & $\left(\begin{array}{lll}5 & 1 & 3\end{array}\right)$ & 1.84 & 1.8388 & 18.25 & & 3.01 & 1.99 & $87-0374$ \\
\hline \multirow{6}{*}{ Annealed at $513 \mathrm{~K}$} & As & $\left(\begin{array}{lll}0 & 3 & 4\end{array}\right)$ & 1.312 & 1.310 & 14.64 & 14.64 & 4.66 & 2.47 & $85-1712$ \\
\hline & \multirow{2}{*}{$\mathrm{Te}$} & $\left(\begin{array}{lll}0 & 1 & 1\end{array}\right)$ & 2.248 & 2.2329 & 18.27 & \multirow{2}{*}{22.00} & 2.99 & 1.98 & 79-0736 \\
\hline & & $\left(\begin{array}{lll}1 & 1 & 1\end{array}\right)$ & 2.039 & 2.0349 & 25.71 & & 1.51 & 1.41 & $85-0556$ \\
\hline & \multirow{3}{*}{$\mathrm{As}_{2} \mathrm{Te}_{3}$} & $\left(\begin{array}{lll}2 & 0 & 2\end{array}\right)$ & 3.914 & 3.8996 & 21.16 & \multirow{3}{*}{21.26} & 2.23 & 1.71 & $75-1470$ \\
\hline & & $\left(\begin{array}{lll}6 & 0 & 1\end{array}\right)$ & 2.363 & 2.3652 & 23.36 & & 1.83 & 1.55 & $75-1470$ \\
\hline & & $\left(\begin{array}{lll}5 & 1 & 3\end{array}\right)$ & 1.84 & 1.8388 & 19.28 & & 4.22 & 2.35 & $87-0374$ \\
\hline
\end{tabular}

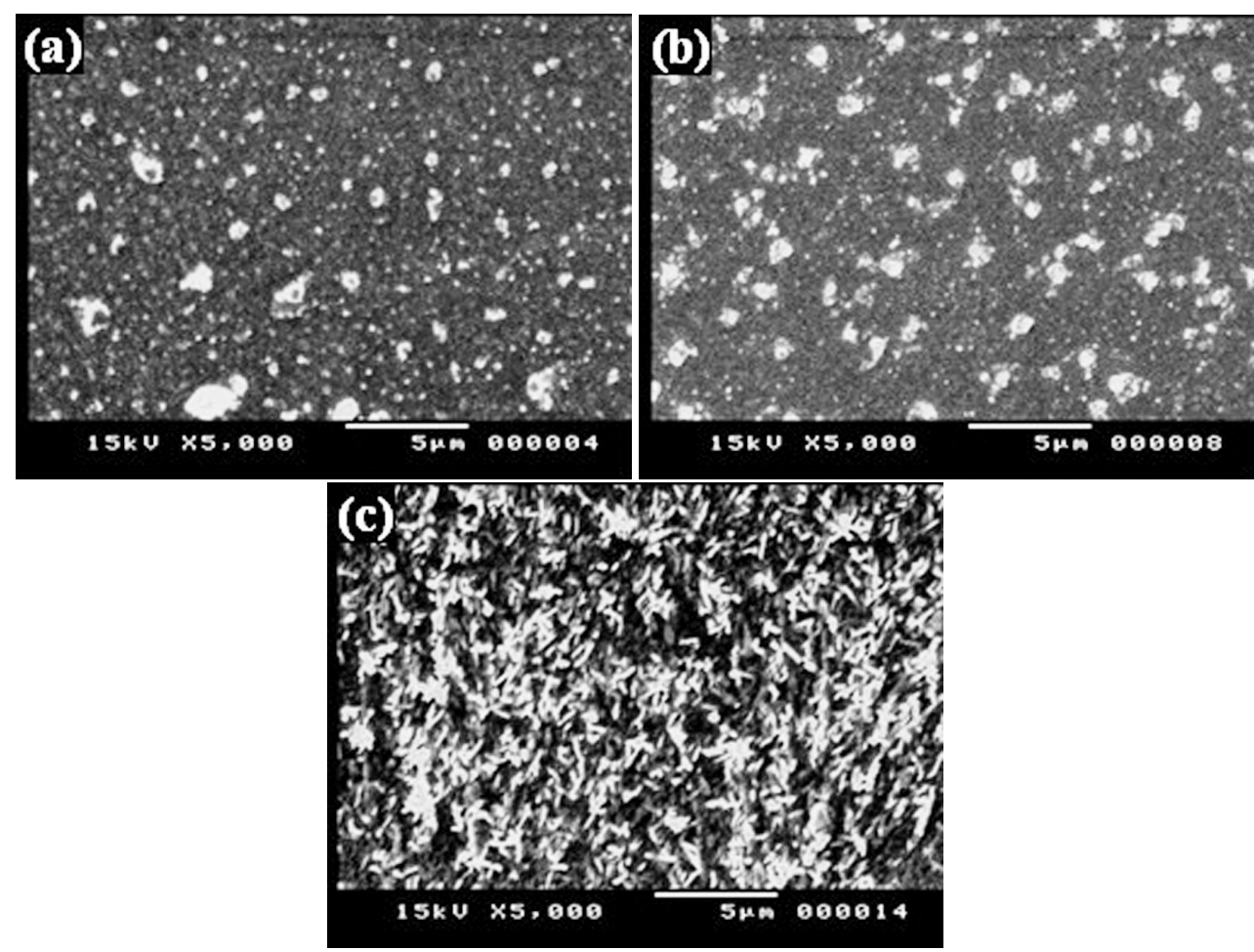

Fig. 3. SEM images showing the surface morphology of $\mathrm{As}_{30} \mathrm{Te}_{70}$ thin films annealed at (a) $433 \mathrm{~K}$, (b) $473 \mathrm{~K}$, and (c) $513 \mathrm{~K}$ for $1 \mathrm{~h}$.

the annealing temperature, $\mathrm{E}_{\mathrm{g}}$ increased. According to literature, with increasing annealing temperature, bigger grain size and lower strain, the optical energy gap $E_{g}$ subsequently decreases [26,33].
In the exponential edge region, $\alpha<10^{4} \mathrm{~cm}^{-1}$, the absorption coefficient is governed by Urbach relation [34]:

$$
\alpha(v)=\alpha_{o} e^{\left(\frac{h v}{E_{e}}\right)}
$$




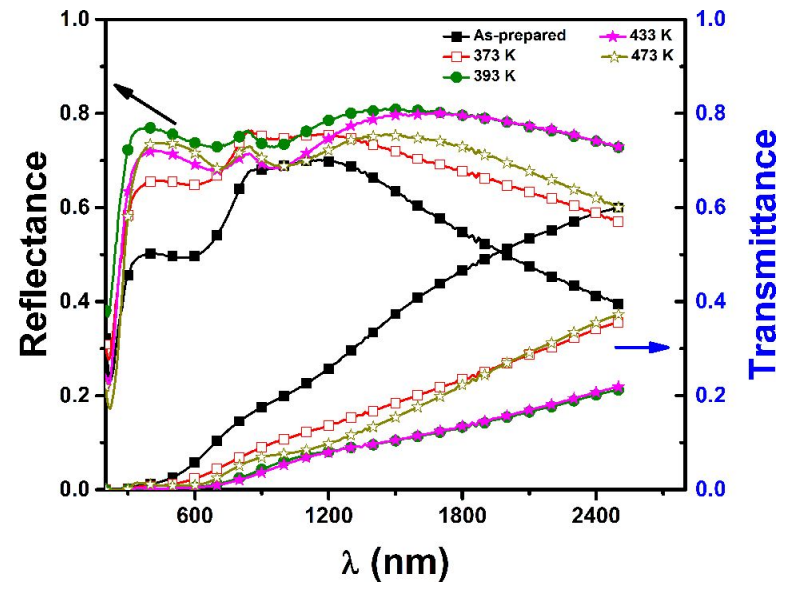

Fig. 4. Plot of the transmittance (T) and reflectance (R) versus the wavelength $(\lambda)$ for the as-prepared and annealed $\mathrm{As}_{30} \mathrm{Te}_{70}$ thin films.

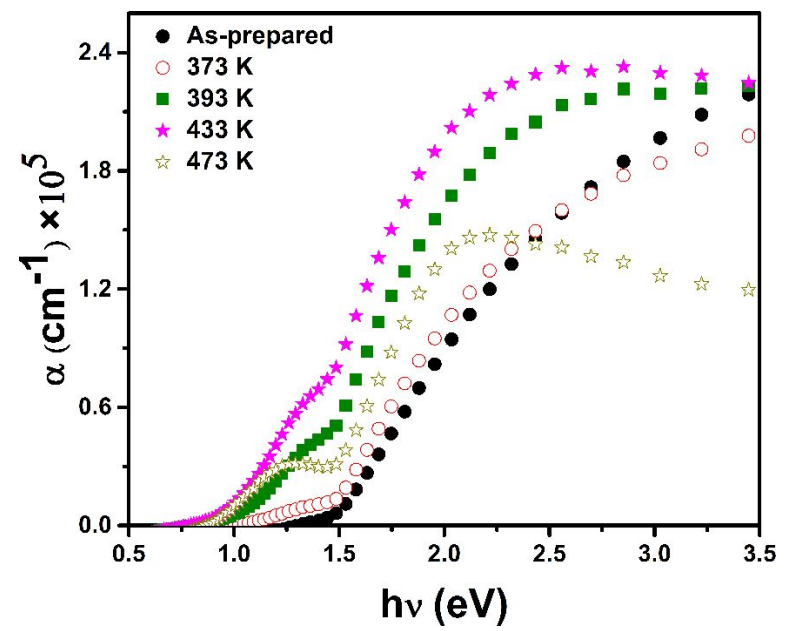

Fig. 5. Plot of the absorption coefficient $(\alpha)$ versus the photon energy $\mathrm{h} v$ for the as-prepared and annealed $\mathrm{As}_{30} \mathrm{Te}_{70}$ thin films.

where $\alpha_{0}$ is a constant and $E_{e}$ is the Urbach energy interpreted as the width of the tails of localized states in the band gap. The linear dependence of $\ln \alpha$ on the photon energy is shown in Fig. 7, while the estimated values of $E_{e}$, as a function of annealing temperature are shown in Fig. 8. The errors of the estimated $\mathrm{E}_{\mathrm{e}}$ was about $\pm 0.5 \mathrm{meV}$. It is observed from Fig. 8 that the band tail width increases from $23 \mathrm{meV}$ to $44 \mathrm{meV}$ as the annealing temperature increases up to $433 \mathrm{~K}$. However, at higher annealing temperature $\mathrm{E}_{\mathrm{e}}$

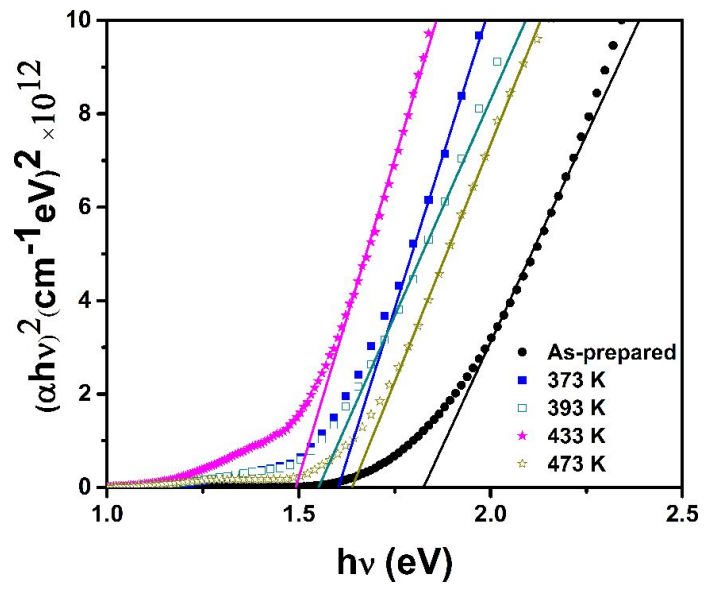

Fig. 6. Plot of $(\alpha \mathrm{h} v)^{2}$ versus hv for the as-prepared and annealed $\mathrm{As}_{30} \mathrm{Te}_{70}$ thin films. The straight lines are a linear fit of the absorption edges.

decreases. The decrease in the optical energy gap and the subsequent increase in localized states tails with the annealing temperature might be due to the presence of surface dangling bonds around the crystallites [35].

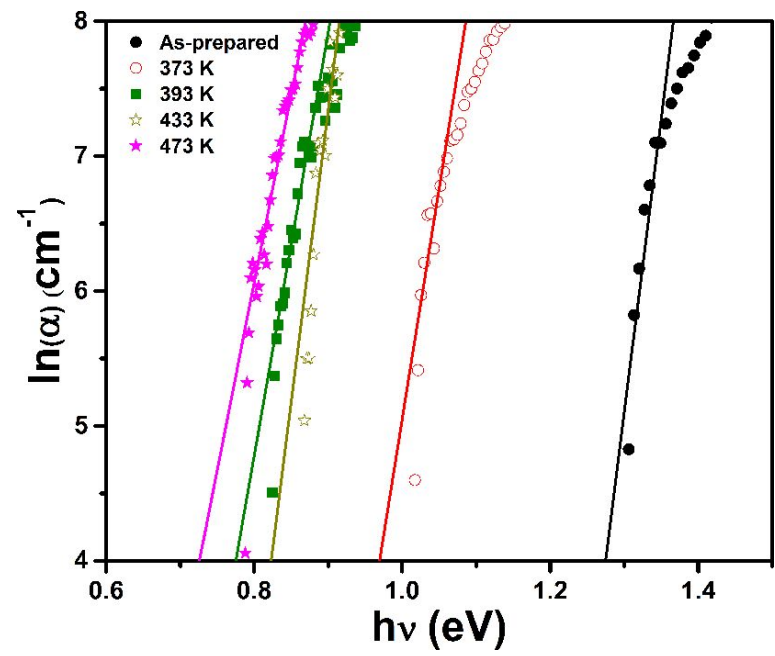

Fig. 7. Plot of $\ln (\alpha)$ versus the photon energy (hv) for the as-prepared and annealed $\mathrm{As}_{30} \mathrm{Te}_{70}$ thin films. The straight lines are a linear fit of Urbach tails.

Previous studies have indicated that near-ideal amorphous solids crystallize under heat treatment and that in the process of crystallization, dangling bonds are produced around the surface 


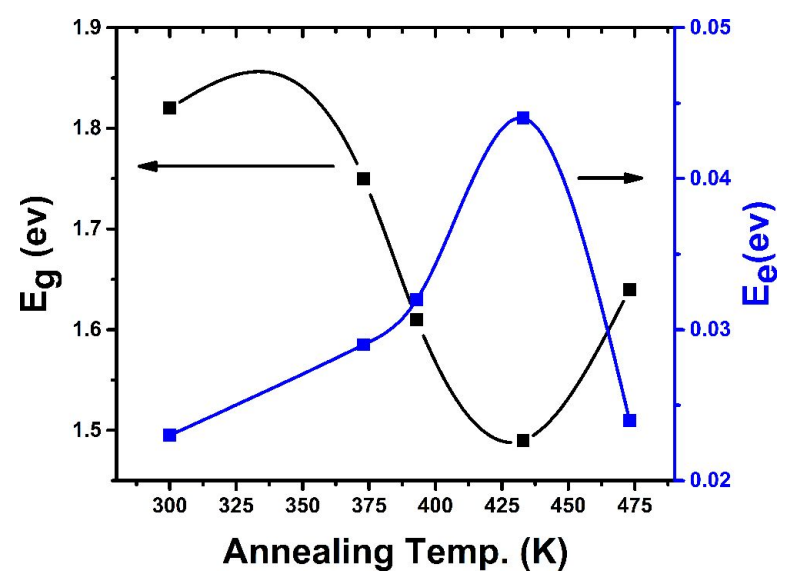

Fig. 8. Plot of the band gap $\left(\mathrm{E}_{\mathrm{g}}\right)$ and width of localized states $\left(\mathrm{E}_{\mathrm{e}}\right)$ versus the annealing temperature for $\mathrm{As}_{30} \mathrm{Te}_{70}$ thin films. The solid curves are guides to the eye.

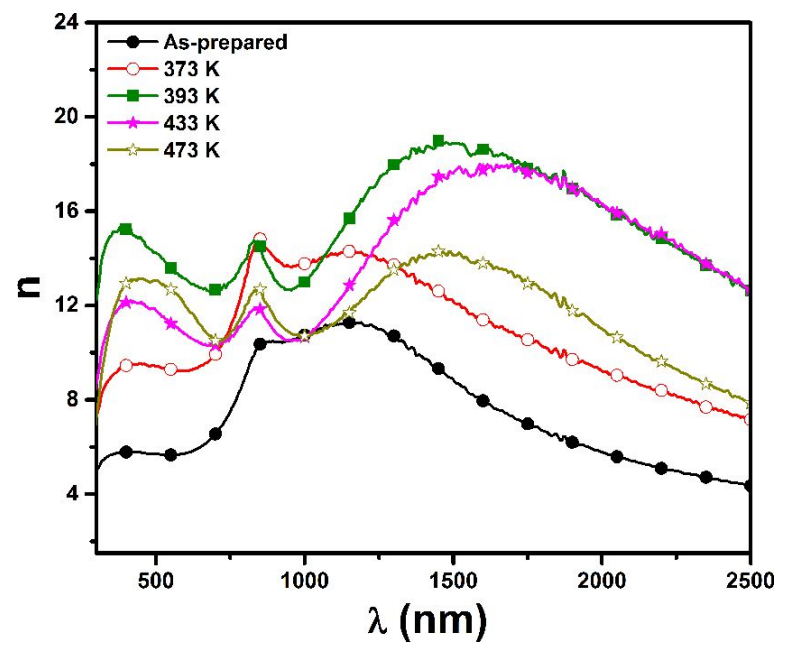

Fig. 9. Plot of the refractive index (n) versus the wavelength $(\lambda)$ for the as-prepared and annealed $\mathrm{As}_{30} \mathrm{Te}_{70}$ thin films.

of the crystallites $[35,36]$. Further heat treatment causes the crystallites to break down [36] into smaller crystals thereby increasing the number of surface dangling bonds. These dangling bonds are responsible for the formation of various defects in highly polycrystalline solids, and their number increases with increasing the annealing temperature. The concentration of localized states in the band structure also increases gradually. Hence, the heat treatment of the films causes an increase in the width of localized states thereby reducing the optical energy gap. Further thermal annealing above the first crystallization temperature reduces the unsaturated defects, and consequently a large number of saturated bonds are produced. Lower number of unsaturated defects decrease the density of localized states in band structure which consequently increases the optical energy gap. The fact that the band gap and the refractive index of amorphous films change upon annealing near the crystallization temperature is expected due to the partial phase change as confirmed by the DSC and XRD analysis.

\subsubsection{Dispersion optical constants}

The refractive index (n), and extinction coefficient $\left(\mathrm{k}_{\mathrm{ex}}\right)$ of the studied films have been estimated using the following relations $[37,38]$ :

$$
\begin{gathered}
R=\frac{(n-1)^{2}+k_{\mathrm{ex}}^{2}}{(n+1)^{2}+k_{\mathrm{ex}}^{2}} \\
k_{e x}=\frac{\alpha \lambda}{4 \pi}
\end{gathered}
$$

The spectral dependence of $\mathrm{n}$ and $\mathrm{k}_{\mathrm{ex}}$ on the wavelength for as-prepared and annealed films are shown in Fig. 9 and Fig. 10, respectively. The refractive index has a maximum value $\left(\mathrm{n}_{\max }\right)$ at a wavelength $\lambda_{c}$ which shifts towards a higher value as the annealing temperature increases (Fig. 9). Furthermore, the extension coefficient decreases with increasing the wavelength. The increase in $n$ and $k_{e x}$ with the annealing temperature may be due to bigger particle size obtained at higher annealing temperature.

Other optical parameters such as the real $\epsilon_{\mathrm{r}}$ and imaginary $\epsilon_{i}$ parts of dielectric constants of the investigated films are given by:

$$
\varepsilon_{r}=n^{2}-k^{2} ; \varepsilon_{i}=2 n k
$$

The obtained values of both $\epsilon_{\mathrm{r}}$ and $\epsilon_{\mathrm{i}}$ increase as the annealing temperature increases as shown in Fig. 11. In addition, the dispersion of refractive index was analyzed using the concept 


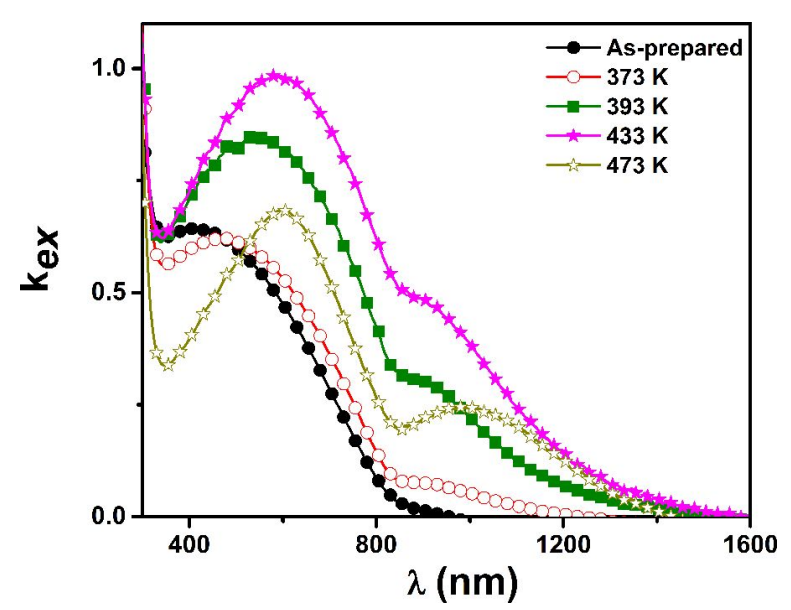

Fig. 10. Plot of extinction coefficient $\left(\mathrm{k}_{\mathrm{ex}}\right)$ versus the wavelength $(\lambda)$ for the as-prepared and annealed $\mathrm{As}_{30} \mathrm{Te}_{70}$ thin films.

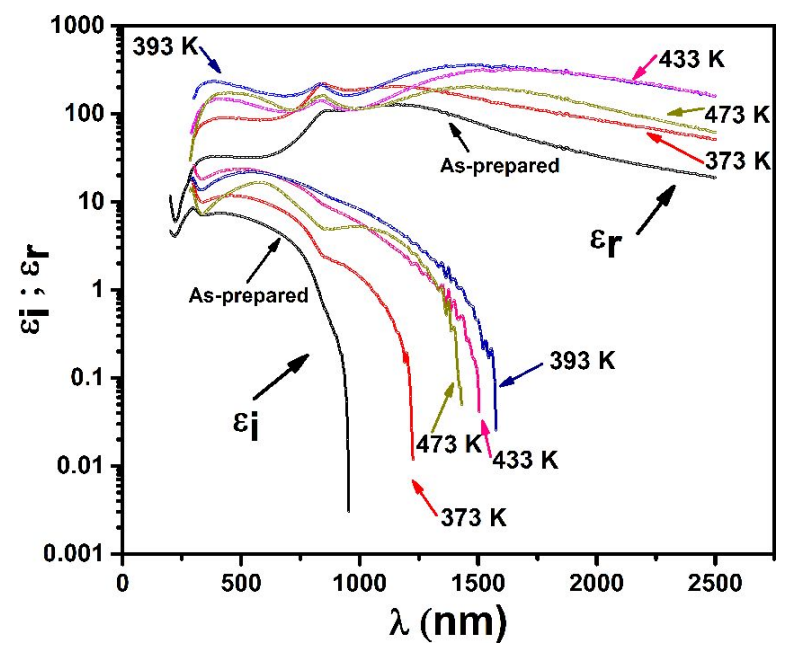

Fig. 11. Semi-logarithmic plot of imaginary $\left(\epsilon_{i}\right)$ and real $\left(\epsilon_{\mathrm{r}}\right)$ part of dielectric constant versus the wavelength $(\lambda)$ for the as-prepared and annealed $\mathrm{As}_{30} \mathrm{Te}_{70}$ thin films.

of a single oscillator which can be expressed by Wemple-DiDomenico relationship [39]:

$$
n^{2}=1+\frac{E_{d} E_{0}}{E_{0}^{2}-E^{2}}
$$

where $\mathrm{E}_{0}$ is a single oscillator energy, considered as an average energy gap, $E_{d}$ is the dispersion energy which measures the average strength of interband optical transitions and $\mathrm{E}$ is the photon energy. By plotting $\left(n^{2}-1\right)^{-1}$ against $E^{2}$, straight lines with a slope $\left(\mathrm{E}_{0} \mathrm{E}_{\mathrm{d}}\right)^{-1}$ and intercept $\mathrm{E}_{0} / \mathrm{E}_{\mathrm{d}}$ were obtained. The errors in the estimated values of $E_{0}$ and $\mathrm{E}_{\mathrm{d}}$ were $\pm 5 \mathrm{meV}$ and $\pm 0.5 \mathrm{eV}$, respectively. From Table 3, it is observed that while $\mathrm{E}_{0}$ decreases with increasing the annealing temperature, $\mathrm{E}_{\mathrm{d}}$ increases. This behavior might be attributed to increased rate of diffusion of atoms which, in turn, raises the number of atoms at interstitial sites leading to impurity type scattering centers.

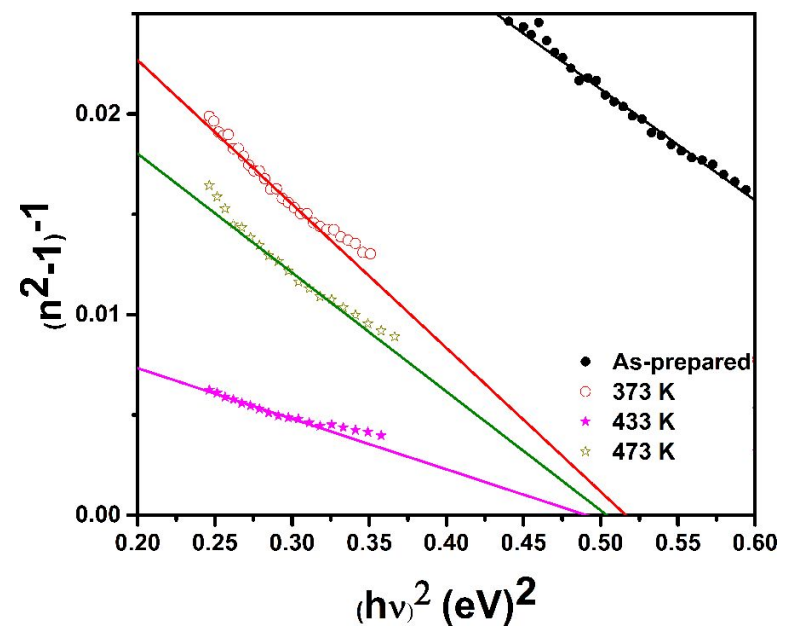

Fig. 12. Plots of $\left(n^{2}-1\right)^{-1}$ versus $(h v)^{2}$ for the asprepared and annealed $\mathrm{As}_{30} \mathrm{Te}_{70}$ thin films.

To calculate the high frequency dielectric constant $\epsilon_{\infty}$, we analyzed the refractive index data using two procedures. In the first procedure, the contribution of free carriers and the lattice vibration modes of dispersion were included into the relation between the lattice high frequency dielectric constant and refractive index as given by the following equation [40]:

$$
n^{2}=\varepsilon_{L}-\left(\frac{e^{2}}{4 \pi^{2} c^{2} \varepsilon_{0}}\right)\left(\frac{N}{m^{*}}\right) \lambda^{2}
$$

where $\mathrm{e}$ is the electronic charge, $\epsilon_{\mathrm{L}}$ is the lattice dielectric constants, $\epsilon_{0}$ is the vacuum permittivity $\left(8.854 \times 10^{-12} \mathrm{~F} / \mathrm{m}\right), \frac{\mathrm{N}}{\mathrm{m}^{*}}$ is the ratio of free carrier concentration $\mathrm{N}$ to the effective electron mass $\mathrm{m}^{*}$, and $c$ is the speed of light. The plot of $n^{2}$ versus $\lambda^{2}$ for the samples is shown in Fig. 13 where $\varepsilon_{L}$ is obtained from the intercept and $\frac{\mathrm{N}}{\mathrm{m}^{*}}$ from the slope. Both $\epsilon_{\mathrm{L}}$ and $\frac{\mathrm{N}}{\mathrm{m}^{*}}$ increase with increasing the annealing temperature (Table 3 ). This result has been 
Table 3. Dispersion parameters for as-prepared and annealed $\mathrm{As}_{30} \mathrm{Te}_{70}$ thin films.

\begin{tabular}{cccccccc}
\hline $\begin{array}{c}\text { Annealing } \\
\text { temperature }[\mathrm{K}]\end{array}$ & $\begin{array}{c}\mathrm{E}_{\mathrm{o}} \\
{[\mathrm{eV}]}\end{array}$ & $\begin{array}{c}\mathrm{E}_{\mathrm{d}} \\
{[\mathrm{eV}]}\end{array}$ & $\begin{array}{c}\lambda_{0} \\
{[\mathrm{~nm}]}\end{array}$ & $\begin{array}{c}\mathrm{S}_{\mathrm{o}} \times 10^{13} \\
{\left[\mathrm{~m}^{-2}\right]}\end{array}$ & $\epsilon_{\mathrm{L}}$ & $\epsilon_{\infty}$ & $\begin{array}{c}\mathrm{N} / \mathrm{m}^{*} \times 10^{57} \\
{\left[\mathrm{~m}^{-3} \cdot \mathrm{kg}^{-1}\right]}\end{array}$ \\
\hline \hline As- prepared & 0.99 & 19.18 & 957.12 & 5.68 & 49.09 & 35.02 & 5.97 \\
373 & 0.97 & 20.34 & 905.78 & 11.78 & 127.13 & 97.65 & 15.03 \\
433 & 0.85 & 56.64 & 677.88 & 56.25 & 417.22 & 348.84 & 50.71 \\
473 & 0.94 & 23.75 & 902.67 & 15.68 & 181.93 & 128.72 & 23.74 \\
\hline
\end{tabular}

observed in many chalcogenide glasses [26, 31]. The increase in the values of $\epsilon_{\mathrm{L}}$ and $\frac{\mathrm{N}}{\mathrm{m}^{*}}$ with the annealing temperature might be attributed to the increased free carrier concentration at higher annealing temperature.

The second procedure for calculating the long wavelength refractive index $\epsilon_{\infty}$ is based on the dispersion arising from the bond carriers in an empty lattice. In this procedure, $\epsilon_{\infty}=\mathrm{n}_{\infty}^{2}$ can be calculated by applying the following classical dispersion relation using the single term Sellmeir oscillation [41]:

$$
\frac{n_{\infty}^{2}-1}{n^{2}-1}=1-\left(\frac{\lambda_{0}}{\lambda}\right)^{2}
$$

where $\lambda_{0}$ is the average oscillator wavelength. By re-arranging equation 13 , we have:

$$
\left(n^{2}-1\right)^{-1}=C-\frac{1}{S_{0}} \lambda^{-2}
$$

Here, $S_{0}=\frac{\left(\mathrm{n}_{\infty}^{2}-1\right)}{\lambda_{0}^{2}}$ is the average oscillator strength and $\mathrm{C}=\frac{1}{\left(\mathrm{n}_{\infty}^{2}-1\right)}$ is a constant. The plots of $\left(n^{2}-1\right)^{-1}$ versus $\lambda^{-2}$ for the studied films are shown in Fig. 14, while $\epsilon_{\infty}, \lambda_{0}$ and $S_{0}$ are tabulated in Table 3. The errors of the estimation of these parameters do not exceed $2 \%$. The average oscillator strength increases with the annealing temperature up to $433 \mathrm{~K}$ and then decreases. In contrary, the value of the average oscillator wavelength decreases with the annealing temperature up to $433 \mathrm{~K}$ and then increases up to $473 \mathrm{~K}$. This behavior may be attributed to the increase in the carrier concentration in the annealed films. In addition, for the range of the considered annealing temperatures, the values of $\epsilon_{\mathrm{L}}$ are higher than those of $\epsilon_{\infty}$.

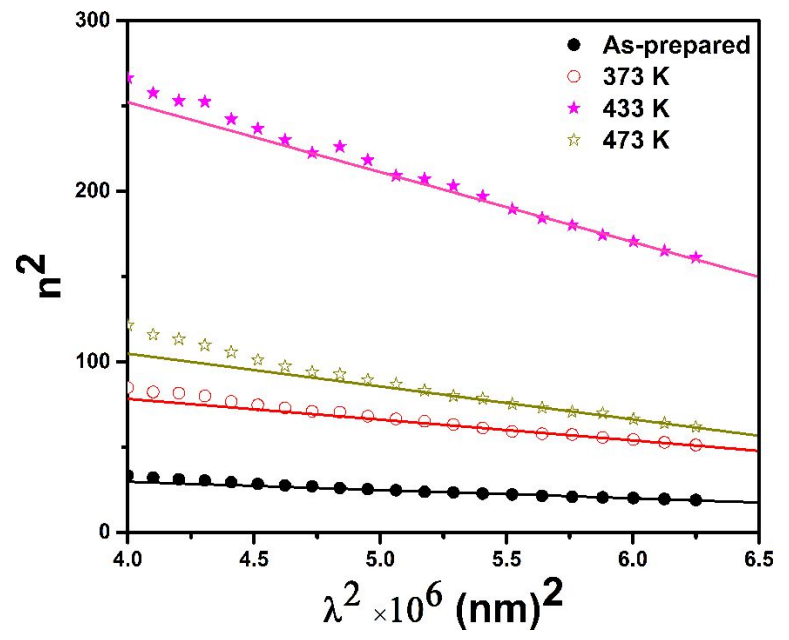

Fig. 13. Plots of $n^{2}$ versus $\lambda^{2}$ for the as-prepared and annealed $\mathrm{As}_{30} \mathrm{Te}_{70}$ thin films.

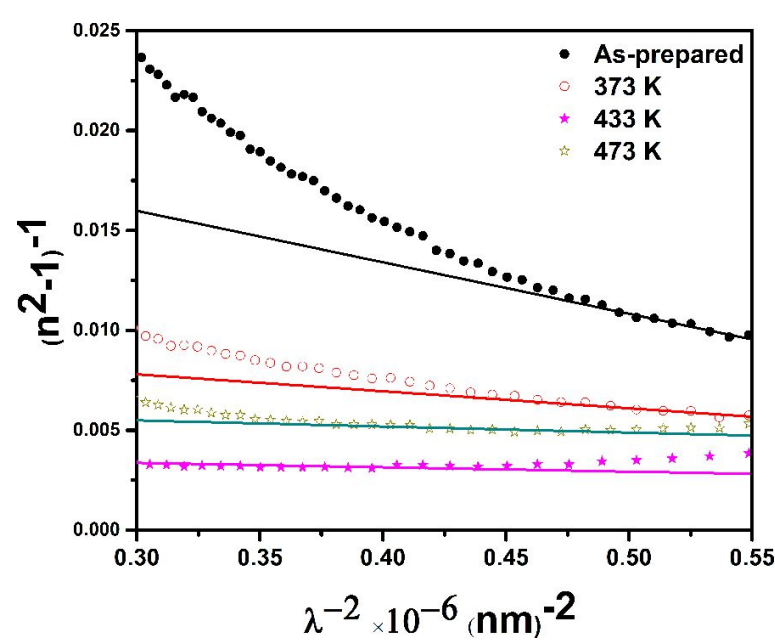

Fig. 14. Plots of $\left(n^{2}-1\right)^{-1}$ versus $\lambda^{-2}$ for the asprepared and annealed $\mathrm{As}_{30} \mathrm{Te}_{70}$ thin films.

In summary, these results indicate that the structural and optical properties of $\mathrm{As}_{30} \mathrm{Te}_{70}$ thin films are significantly affected by the annealing temperature. However, the optical and dispersion 
parameters exhibit opposite behavior upon annealing. It was also observed that $433 \mathrm{~K}$ could be considered as an inversion annealing point, especially for the optical characteristics. This is probably because $433 \mathrm{~K}$ lies after the first crystallization peak according to the DSC traces. The XRD spectra confirmed transformation of two new phases (Te and $\left.\mathrm{As}_{2} \mathrm{Te}_{3}\right)$ from semiconductor to the metallic state [3]. This observed transformation might be responsible for the changes occurred in all optical and dispersion parameters of the samples annealed above $433 \mathrm{~K}$.

\section{Conclusions}

$\mathrm{As}_{30} \mathrm{Te}_{70}$ thin films were deposited onto glass substrates under a vacuum of $1.33 \times 10^{-3}$ Pa using thermal evaporation technique. Both the asprepared and annealed films were characterized by different techniques such as XRD, SEM, and DSC. The XRD results showed that the as-prepared films are amorphous in nature, while the annealed samples exhibit many crystalline peaks, confirming the amorphous-crystallization transformation. Moreover, the XRD data revealed the transformation of two new phases ( $\mathrm{Te}$ and $\mathrm{As}_{2} \mathrm{Te}_{3}$ ) from semiconductor to the metallic state. On the other hand, the presented optical results indicate that optical properties of $\mathrm{As}_{30} \mathrm{Te}_{70}$ thin films are significantly affected by the thermal annealing. For example, the direct band gap decreased from $1.82 \mathrm{eV}$ to $1.49 \mathrm{eV}$ with increasing the annealing temperature up to $433 \mathrm{~K}$ and after that, it increased with further increase in the annealing temperature. Such behavior was observed in all optical parameters of the investigated films. This means that the optical parameters exhibit opposite behavior upon annealing at $433 \mathrm{~K}$. This could be attributed to the semiconductor metallic transformation observed in the annealed films.

\section{References}

[1] Zallen R., Penchina C.M., Am. J. Phys., 54 (1986), 862.

[2] Burina A., Lecante P., Mosset A., Galy J., TonNerre J.M., RaOUX D., J. Non-Cryst. Solids, 212 (1997), 23.
[3] Titus S.S.K., Asokan S., RAMAKRishna R., Gopal E.S.R., Philos. Mag. B, 62 (1990), 553.

[4] Endo H., Hoshino H., IKemoto H., Miyanaga T., J. Phys-Condens. Mat., 12 (2000), 6077.

[5] Kaseman D.C., Hung I., Lee K., Kovnir K. Gan Z., Aitken B., Sen S., J. Phys. Chem. B, 119 (2015), 2081.

[6] Seddon A.B., J. Non-Cryst. Solids, 184 (1995), 44.

[7] Davis E.A., Motт N.F., Philos. Mag., 22 (1970), 0903.

[8] TVERJANOVICH A., YagodkinA M. StryKanov V., J. Non-Cryst. Solids, 223 (1998), 86.

[9] Faigel GY., Granasy L., Vincze I., DE WAARD H., J. Non-Cryst. Solids, 57 (1983), 411.

[10] Toscani S., Dugue J., CeOlin R., Thermochim. Acta, 196 (1992), 191.

[11] Hafiz M.M., Moharram A.H., Abu-Sehly A.A., Appl. Surf. Sci., 115 (1997), 203.

[12] Murugavel S., Acharya K.V., Asokan S., J. NonCryst. Solids, 191 (1995), 327.

[13] QUinN R.K., Mater. Res. Bull., 9 (1974), 803.

[14] Titus S.S.K., Asokan S., Gopal E.S.R., Solid State Commun., 83 (1992), 745.

[15] Cornet J., Rossier D., J. Non-Cryst. Solids, 12 (1973), 85.

[16] Cornet J., Rossier D., J. Non-Cryst. Solids, 12 (1973), 61.

[17] Kim S., Kiм H., Choi S., J. Alloy. Compd., 667 (2016), 91

[18] Jovari P., Lucas P., Yang Z., Bureau B., Kaban I., Beuneu B., Panatlei C., Bednarcik J., J. Non-Cryst. Solids, 433 (2016), 1.

[19] LuCas P., Coleman G.J., Kaseman D.C., YAng Z., Hung I., Gan Z., Sen S., J. Non-Cryst. Solids, 432 (2016), 527.

[20] Tverjanovich A., Rodionov K., Bychkov E., $J$. Solid State Chem., 190 (2012), 271.

[21] Dongol M., Hafiz M.M., Abou-Zied M., Elhady A.F., Appl. Surf. Sci., 185 (2001), 1.

[22] Manikandan N., Asokan S., J. Non-Cryst. Solids, 353 (2007), 1247.

[23] Eifert J.R., Peretti E.A., J. Mater. Sci., 3 (1968), 293.

[24] Patterson A.L., Phys. Rev., 56 (1939), 978.

[25] Abdel-Rahim M.N., Abdel-Latif A.Y., Soltan A.S., Physica B, 291 (2000), 41.

[26] ABDEl-RAhim M.A., Hafiz M.M., Mahmoud A.Z., Chalcogenide Lett., 12 (2015), 263.

[27] Alterkop B., Parkansky N., Goldsmith S., BoXMAn R.L., J. Phys. D, 36 (2003), 552.

[28] Pankove J.I., Optical processes in semiconductors, Courier Corporation, 2012.

[29] El-Nahass M.M., Zeyada H.M., AZIZ M.S., MAKHLOUf M.M., Opt. Laser Technol., 39 (2007), 347.

[30] Abdel-Rahim M.A., J. Phys. Chem.Solids, 60 (1999), 29. 
[31] Abdel-Rahim M.A., Abdel-Lahtief A.Y., [37] Vincent R.K., Hunt G.R., Appl. Opt., 7 (1968), 53. Rashad M., Abdelazim N.M., Mat. Sci. Semicon. Proc., 20 (2014), 27.

[32] Al-Agel F.A., Nanoscale Res. Lett., 8 (2013), 1.

[33] El-Sebait A.A., Khan S.A., Al-Marzouki F.M., 38] Gravesteijn D.J., Appl. Opt., 27 (1988), 736.

[39] Wemple S.H., Phys. Rev.B, 7 (1973), 3767.

[40] Zemel J.N., Jensen J.D., Schoolar R.B., Phys. Rev., 140 (1965), A330.

FAIDAH A.S., Al-Ghamdi A.A., J. Lumin., 132 (2012), 2082.

[41] Walton A.K., Moss T.S., Proceed. Phys. Soc., 81 (1963), 509.

[34] Urbach F., Phys. Rev., 92 (1953), 1324.

[35] Chaudhuri S., Biswas S.K., Choudhury A., Goswami K., J. Non-Cryst. Solids, 54 (1983), 179.

[36] Hasegawa S., Kitagawa M., Solid State Commun.,

Received 2016-07-23 27 (1978), 855. 